Published in final edited form as:

Clin Gerontol. 2021 ; 44(2): 192-205. doi:10.1080/07317115.2018.1536687.

\title{
The Relationship Between Maladaptive Personality and Social Role Impairment in Depressed Older Adults in Primary Care
}

\author{
Aliza Romirowsky, \\ Ferkauf Graduate School of Clinical Psychology, Yeshiva University \\ Richard Zweig, \\ Ferkauf Graduate School of Clinical Psychology, Yeshiva University, Albert Einstein College of \\ Medicine \\ Lauren Glick Baker, \\ Ferkauf Graduate School of Clinical Psychology, Yeshiva University \\ Jo Anne Sirey \\ Department of Psychiatry, Weill Cornell Medicine
}

\begin{abstract}
Objective: Personality pathology is associated with impaired social functioning in adults, though further evidence is needed to examine the individual contributions of personality traits and processes to social functioning in depressed older adults. This study is a secondary analysis examining the relationship between maladaptive personality traits and processes and social role impairment in depressed older adults in primary care.
\end{abstract}

Methods: Participants $(\mathrm{N}=56)$ were $77 \%$ female and ranged in age between 55-89 ( $M=66.82$, $S D=8.75)$. Personality pathology was measured by maladaptive traits (NEO-FFI) and processes (Inventory of Interpersonal Problems; IIP-PD-15). Individual variable as well as combined predictive models of social role impairment were examined.

Results: Higher neuroticism $(\beta=0.30, p<.05)$, lower agreeableness $(\beta=-0.35 p<.001)$ and higher IIP-PD-15 ( $\beta=0.28, p<.01)$ scores predicted greater impairment in social role functioning. A combined predictive model of neuroticism and IIP-PD-15 scores predicted unique variance in social role impairment $\left(R^{2}=.71\right)$.

Conclusion: These results link select personality traits and interpersonal processes to social role impairment, suggesting that these are indicators of personality pathology in older adults.

Clinical Implications: These findings lend preliminary support for clinical screening of personality pathology in depressed older adults utilizing both personality trait and process measures.

\section{Keywords}

Personality; Depression; Older Adult; Primary Care 


\section{Introduction}

While risk and protective factors for certain mental health problems have been well studied in older adults (e.g. depression; Fiske, Wetherell, \& Gatz, 2009), correlates of personality pathology remain less well understood, despite emerging evidence of the significant impact that personality has on the functioning of older adults (Balsis, Zweig, \& Molinari, 2015; Oltmanns \& Balsis, 2011; Powers \& Oltmanns, 2012). Increasingly, psychologists have noted the importance of examining both clinical symptoms and functional impairment when studying psychopathology (Ustun \& Kennedy, 2009). In particular, social dysfunction is a relatively enduring outcome associated with personality pathology (Oltmanns \& Balsis, 2011) that is oftentimes distressing for both individuals with personality pathology and/or the people with whom they interact (e.g. family, clinicians, friends). Although DSM models of personality pathology incorporate social role impairment (American Psychiatric Association, 2013), empirical research linking the two, or specifying personality traits and processes most associated with impairment, has lagged, particularly in studies of older adults.

\section{Models of Personality Pathology}

Personality functioning can be conceptualized using various frameworks. The framework most commonly utilized in clinical settings when examining maladaptive personality is that of personality disorder (PD), as delineated in the Diagnostic and Statistical Manual (DSM-5; American Psychiatric Association, 2013). While recent nationally representative surveys have indicated that PDs are common in older adults $(8.1-14.5 \%$ prevalence rate of at least one PD; Reynolds, Pietrzak, El-Gabalawy, Mackenzie, \& Sareen, 2015; Schuster, Hoertel, Le Strat, Manetti \& Limosin, 2013), there are particular challenges associated with the use of the DSM PD framework (e.g. age bias; Balsis, Gleason, Woods, \& Oltmanns, 2007) and more generally, the study of personality pathology, in later life (e.g. cohort effects; Zweig \& Agronin, 2011). Therefore, other models of personality functioning are particularly relevant when studying older adults.

Moving beyond the DSM framework, alternate models of personality have been developed in order to comprehensively conceptualize personality functioning. In addition to cultural and evolutionary influences, McAdams and Pals (2006) presented a framework of personality functioning that incorporates dispositional traits, characteristic adaptations and life narratives. In this model, personality traits speak to the relative consistency of an individual's inner experience and behavior over time. Next, characteristic adaptations, or personality processes (Seidlitz, 2001), are considered to capture relative variability in personality functioning as individuals engage with various contexts and motivational influences in their social world, such as patterned ways of regulating emotions or engaging in interpersonal relationships. The third level of personality functioning is that of life narrative. Hooker and McAdams (2003) have applied this model to older adults, though empirical research in this area is necessary.

Abundant research has investigated personality functioning at the dispositional trait level, often utilizing a continuous trait model such as the Five Factor Model (FFM; McCrae \& John, 1992). While the FFM captures normative personality functioning, recent research 
suggests that extreme manifestations of FFM traits may be markers of personality pathology (Kreuger \& Eaton, 2010; Piedmont, Sherman, \& Sherman, 2012; Samuel \& Gore, 2012). FFM trait patterns appear to differentially match PD characteristics in ways that are consistent with the prototypal features of the disorder (Saulsman \& Page, 2004). In fact, significant evidence suggests that dimensional measurements of personality traits are most predictive of relevant outcomes (Kruger \& Eaton, 2010; Ozer \& Benet-Martinez, 2006; Roberts, Kuncel, Shiner, Caspi, \& Goldberg, 2007).

Within the FFM framework, both neuroticism and agreeableness emerge as particularly related to personality pathology. Neuroticism appears to reflect tendencies toward emotional stability versus instability, in that high neuroticism is conceptualized as a characteristic proneness to high negative affect (McCrae \& John, 1992), and is a factor commonly associated with psychopathology in mixed-aged (Kotov, Gamez, Schmidt, \& Watson, 2010; Weinstock \& Whisman, 2006) and older adult (e.g. Duberstein, Pálsson, Waern, \& Skoog, 2008; Koorevaar et al., 2013) samples. Agreeableness appears to reflect tendencies toward altruism/caring versus hostility/antagonism (McCrae \& John, 1992). Research on FFM markers of PD has generally found that higher neuroticism and lower agreeableness is associated with PD. In a meta-analysis of mixed-aged samples, the combination of high neuroticism and low agreeableness was associated with some PDs (Saulsman \& Page, 2004). Similarly, Morey and colleagues (2002) found that some individuals with PD shared a common FFM configuration of high levels of neuroticism paired with low levels of agreeableness and conscientiousness.

The second level of McAdams and Pals' (2006) model, characteristic adaptations, can be identified in various domains of functioning such as cognition, affectivity, interpersonal functioning, and impulse control (American Psychiatric Association, 2013). Previous research indicates that some areas of personality pathology such as the affectivity, impulsivity, and cognitive domains are susceptible to age-related changes in the expression of personality pathology (Agronin \& Maletta, 2000; Black, Baumgard, \& Bell, 1995; Hunt, 2007; Segal, Zweig, \& Molinari, 2012; Van Alphen, Derksen, Sadavoy, \& Rosowsky, 2012). Notably, one area of relative stability may be interpersonal pathology, as individuals struggling with personality pathology tend to have chronic interpersonal difficulties across the lifespan (Oltmanns \& Balsis, 2011). In studies of mixed-aged adults, a measure of the interpersonal expression of personality pathology (the Inventory of Interpersonal Problems [IIP]) has been shown to differentiate between individuals with and without PDs (Kim \& Pilkonis, 1999; Leising, Rehbein, \& Eckardt, 2009; Morse \& Pilkonis, 2007; Pilkonis, Kim, Proietti, \& Barkham, 1996; Stern, Kim, Trull, Scarpa, \& Pilkonis, 2000). Interpersonal difficulties, traits and social impairment may be among the more consistent indicators of personality pathology, but their inter-relationships have rarely been examined in older adult samples.

\section{Personality Pathology and Social Functional Impairment In Mixed-Aged Samples}

Personality pathology is often comorbid with (Bagby, Quilty \& Ryder, 2008), and adversely impacts mood disorders such as depression. The negative impact of comorbid depression and personality pathology on functional impairment (Markowitz et al., 2007; Skodol et al., 
2005a) and treatment outcomes (Grilo et al., 2010; Markowitz et al., 2007; Meyers et al., 2002) in mixed age adults is well established.

Outside of the context of depression, personality pathology is associated with negative functional outcomes such as impaired physical and psychological health, higher mortality rates, occupational impairment and divorce (Bender at al., 2001; Hengartner, Müller, Rodgers, Rössler \& Ajdacic-Gross, 2014; Ozer \& Benet-Martinez, 2006; Powers \& Oltmanns, 2012; Roberts et al., 2007; Soeteman, Verheul, \& Busschbach, 2008). When studied longitudinally, chronic personality pathology is associated with long-term functional impairment beyond the influence of co-occurring axis-I disorders (Skodol, Johnson, Cohen, Sneed, \& Crawford, 2007). In particular, social dysfunction and interpersonal problems (Oltmanns \& Balsis, 2011; Skodol et al., 2005b) are common. The link between personality pathology and social dysfunction has been found both in clinical (Carpenter, Clarkin, Glick \& Wilner, 1995) and non-clinical (Oltmanns, Melley, \& Turkheimer, 2002) samples of adults, but empirical studies of this relationship in older adults utilizing validated measures of social functioning are lacking.

\section{Personality Pathology and Social Functional Impairment in Older Adults}

Although there is compelling evidence of associations between personality pathology and social dysfunction in mixed age samples, thus far much of the empirical research in older adults regarding the unique impact of personality pathology has focused upon health outcomes in non-clinical samples (e.g. healthcare utilization, physical functioning, medical burden and health decline: Powers \& Oltmanns, 2012 and Chapman, Roberts, Lyness, \& Duberstein, 2013).

Studies that have examined mental health outcomes of personality pathology find that, consistent with findings in mixed-aged populations, clinical samples of older adults with depressive and personality pathology symptoms evidence lower levels of overall functioning, reduced quality of life (Abrams, Alexopoulos, Spielman, Klausner, \& Kakuma, 2001) and poorer treatment response (Gradman, Thompson, \& Gallagher-Thompson, 1999; Vine \& Steingart, 1994). After controlling for depression, high neuroticism has been associated with poorer global cognitive functioning for older adults in primary care (Boyle et al., 2010). Similarly, in older adults with remitted depression, cluster C (i.e. avoidant, dependent, obsessive-compulsive) personality pathology was associated with impaired IADLs, whereas Cluster A (i.e. paranoid, schizoid, schizotypal) or B (i.e. borderline, narcissistic, histrionic, antisocial) pathology was related to difficulties in sociability and relationship satisfaction (Abrams, Spielman, Alexopoulos \& Klausner, 1998). Though this body of research is small, it suggests that personality pathology can have a negative impact on the functioning of older adults even after depressive symptoms have remitted or are statistically controlled. However, these studies solely operationalize personality pathology as either traits or a categorical diagnosis of PD and do not investigate associations between personality processes and relevant outcomes, both of which warrant further attention.

Recent evidence from non-clinical samples of older adults provides support for the preliminary findings found in clinical samples, associating personality pathology with poorer social outcomes. For instance, Gleason, Weinstein, Balsis, and Oltmanns (2014) cite 
emerging evidence from their longitudinal study of a community sample of middle age-older adults (ages 55-64) on the impact of both normative and maladaptive aspects of personality on social and health outcomes. Overall, personality pathology was related to reduced social support, social isolation and loneliness. In the same community sample, borderline personality pathology was predictive of greater aggression toward significant others (Weinstein, Gleason, \& Oltmanns, 2012) and more frequent interpersonal "dependent" stressful life events (Powers, Gleason \& Oltmanns, 2013). These studies suggest a connection between maladaptive personality and poor social functioning in older adults. However, to our knowledge, previous research has not examined the utility of combined predictive models, such as additive models of personality functioning at various levels (e.g. traits and processes) to better predict social role impairment. Such models would not only establish an empirical association between personality pathology and social role impairment and thereby add to the construct validity (Wilson, Stroud, \& Durbin, 2017) of measures of such pathology in older adults, but would also begin to clarify how personality pathology contributes to social functional impairment.

\section{Study Aims}

The current study had two aims. The first aim was to assess for the relationship between aspects of personality pathology, traits (i.e. FFM traits of neuroticism and agreeableness) and processes (i.e. interpersonal problems), and impairment in social role functioning in older adults. We predicted that both maladaptive traits and processes would be associated with overall social role impairment. The second aim was to assess for the utility of combined models of maladaptive personality in predicting social role functioning. We predicted that a combined model of traits and processes would enhance the predictive power of our model assessing for social role impairment. Additionally, since the majority of depressed older adults are treated in primary care settings (Kessler et al., 2010), we reasoned that findings regarding interrelationships between mood, personality and functioning in a depressed, older primary care sample would have high clinical utility.

\section{Method}

The current study is a secondary analysis of a subset of data drawn from the Treatment Initiation Program (TIP) study (MH 087562, PI Sirey) which examined the effectiveness of a medication adherence intervention for depression in older adults in primary care (Sirey et al., 2017; Sirey, Bruce, \& Kales, 2010). The methods delineated below pertain only to the data used in this current investigation.

\section{Participants}

Recruitment and eligibility of participants followed the protocol of the Treatment Initiation Program (TIP) study (Sirey et al., 2017; Sirey et al., 2010). This study utilizes a subset of consecutively recruited participants $(\mathrm{N}=56)$ from one primary care site who completed all relevant study measures for this secondary analysis. 
Procedure

All participants provided informed consent to participate in the study and all data were deidentified. Qualified research assistants administered the research assessments. Assessments for the TIP study were completed at study entry (baseline), as well as 6-, 12-, and 24-week follow-up. This study uses data from the baseline visit as well as the week 12 follow up visit. Due to study design, our study administered the personality process measure over two time periods with 7 items administered at week 1 and 8 items administered at week 12 .

\section{Measures}

Demographic and Clinical Information-Information was obtained by interviews with the participants. Data gathered included date of birth, age, gender, race, marital status, educational and occupational history, current living situation, medical history, and current medications. Disease burden was measured using the Chronic Disease Score (CDS; Clark, Von Korff, Saunders, Baluch, \& Simon, 1995), which was calculated using a weighted algorithm to determine disease severity based on the patient's prescription medications. Depression was measured using the Hamilton Depression Rating Scale (HAM-D; Hamilton, 1960), a clinician administered scale developed to assess the severity of depression symptoms. The HAM-D has been used extensively in samples of older adults in primary care (e.g. Gallo et al., 2007; Sirey, et al., 2010).

\section{Personality Traits and Processes}

\section{Personality traits: NEO- Five Factor Inventory (NEO-FFI) (Costa \& McCrae,} 1992).: This is an extensively studied, objective measure of personality that assesses personality across five domains of the five factor model (FFM): neuroticism (N), extraversion (E), openness (O), agreeableness (A), and conscientiousness (C). Utilizing a Likert scale ranging from 1 (strongly disagree) to 5 (strongly agree), participants rate how well 60 statements describe them. Factor scores are derived by summing the items in each factor. This measure evidences good internal consistency in studies assessing personality in primary care settings ( $\alpha=.73-.88$; Chapman, Lyness \& Duberstein, 2007). In the present study, internal consistencies (Table 1$)$ varied by factor $(a=.50-.78)$. $\mathrm{O}$ and A demonstrated lower levels of internal consistency than expected, which may be attributable to demographic differences between this sample and a comparison sample of older adults (Weiss et al., 2005).

\section{Personality Processes: Inventory of Interpersonal Problems - Personality Disorders (IIP-PD-15; Kim \& Pilkonis, 1999).: The original version of the IIP was 127 items} (Horowitz, Rosenberg, Baer, Ureno, \& Villaseñor, 1988) and was developed to assess interpersonal problems. The IIP-PD-15 utilized in this study, a revised version developed as a brief screen for the presence of PD, is a 15-item screening measure that was distilled from a 47-item version (IIP-PD-47; Pilkonis et al., 1996) using item response theory. The measure assesses interpersonal problems along three dimensions, which were found to be most indicative of the presence of personality disorder: interpersonal sensitivity, interpersonal ambivalence, and aggression. Items from the IIP are rated on a 4-point Likert scale, indicating how distressing the interpersonal problem is for the participant $(0$, not at all - 4 
extremely distressing). Overall scores were derived from a sum of the fifteen IIP items. Analyses of internal consistency for all subscales were strong $(\alpha=>.80$; Kim \& Pilkonis, 1999). While the IIP has been used in older adult samples to measure interpersonal difficulties (Harrison et al., 2010; Szanto et al., 2012) it has not been validated in an older adult sample as a measure for personality pathology. In the current sample, internal consistency for this measure was excellent $(a=.85)$.

\section{Social Role Impairment}

Social Adjustment Scale - Self report (SAS-SR) (Weissman \& Bothwell, 1976;

Weissman \& MHS Staff, 1999).: The SAS-SR, a measure of social role functioning, has 54 items that comprise eight subscales related to the following roles: Work for Pay, Housework (unpaid), Student, Social and Leisure, Family Outside the Home, Primary Relationship, Parental, and Family Unit. There is also a summary scale to measure overall social role adjustment. The SAS-SR items are rated on a Likert scale ranging from 1-5, with higher scores indicating greater social role impairment. As some social role domains may not apply to all participants, subjects only completed items relevant to their daily lives. Summary scores are derived for each domain by calculating the average of all items answered for each participant. The SAS-SR overall score is a mean of all items answered. This scale has demonstrated validity in assessing social functional impairment associated with personality pathology in mixed age samples (Hopwood et al., 2011) and it has demonstrated acceptable psychometric properties in older adult samples with adequate internal reliability (mean a $=.62$ ) and convergent validity with measures of depression (Zweig \& Turkel, 2007). In the current study internal consistencies for each subdomain varied (mean $a=.59$ ). This lower level of internal consistency maybe due to the branching nature of the questionnaire, which reduced the sample size for certain subdomains.

\section{Data Analysis}

The relationship between demographic/clinical variables and our outcome variable, social role impairment, was evaluated to assess for potential confounds. Variables such as gender, race, age, marital status, level of education, occupation status, living situation, depression severity, and chronic illness were examined in relation to social role impairment using correlations (pearson and spearman), t-tests, and ANOVA, as appropriate. Analyses that followed adjusted for significant demographic and clinical variables. Pearson correlations were conducted to examine bivariate relationships among key study variables. Further analyses were only conducted when independent and dependent variables were significantly related.

To evaluate the relationship between personality pathology (traits and processes) and social role impairment, we tested five models using hierarchical multiple regression analyses. All models included relevant demographic and clinical variables: depression severity, occupation status, education level and race. In addition, Model 1 included neuroticism; Model 2 included agreeableness; Model 3 included IIP-PD-15 scores. Additive models of personality factors (combined predictive models of traits and processes) were also explored using hierarchical multiple regression. In addition to the clinical and demographic variables, 
Model 4 included IIP-PD-15 + Neuroticism and Model 5 included IIP-PD-15 + Agreeableness. An alpha value of $\mathrm{p}<.05$ was used for all statistical analyses.

\section{Results}

\section{Descriptive Statistics and Sample Characteristics}

Table 1 displays demographic information for this sample. Study participants $(\mathrm{N}=56)$ had an average age of 66.8 years ( $\mathrm{SD}=8.75$; range $55-89$ ) and the sample was predominantly female $(76.8 \%)$ and white $(60.7 \%)$ with at least some college education $(62.5 \%)$. A majority of the sample was either currently married $(23.2 \%)$ or had previously been married $(46.4 \%)$ and was living with other individuals in their homes (53.6\%). Most participants were either employed or retired (71.4\%) rather than unemployed/on disability. Participants tended to be mildly depressed based on week-12 HAM-D scores $(M=16.5, S D=9.32)$. The mean CDS score for our participants was $3.9(\mathrm{SD}=2.66)$, which is consistent with scores in the average range of self-rated physical health in older adults (Leibson et al., 1999).

Potential demographic and clinical confounds of overall social role impairment were evaluated. Years of completed education was negatively related to social role impairment $(r$ $=-.27, p=.045)$. Non-white participants endorsed greater levels of social role impairment $(M=2.50, S D=.57)$ compared to white participants $(M=2.10, S D=.46), t(54)=3.10, p$ $=.003$, Cohen's $d=.83$. Individuals who were unemployed or on disability $(M=2.55, S D$ $=.59)$ evidenced greater social functional impairment $(t(54)=2.94, p=.005)$ compared to participants who were employed or retired $(M=2.11, S D=.47$, Cohen's $d=.82)$. Depression severity was positively $(r=.68, p<.001)$ associated with social role impairment. Gender, age, living situation, marital status and disease burden were not associated with social role impairment. All relevant confounds were entered as covariates in subsequent analyses.

\section{Associations Between Maladaptive Personality Traits and Processes and Social Role Impairment}

Based upon findings of significant relationships obtained through bivariate analyses (Table 2), we conducted several hierarchical multiple regression analyses to evaluate whether hypothesized NEO-FFI traits (neuroticism and agreeableness) and personality processes (IIP-PD-15 scores) significantly predicted social role impairment after controlling for relevant confounds (Table 3). Findings were consistent with our hypotheses. In Model 1 higher neuroticism predicted greater social role impairment, with neuroticism contributing an additional $4.7 \%$ of the variance, $R^{2}$ change $=.047$, Fchange $[1,50]=7.17, p=.01$. In Model 2 lower agreeableness predicted greater social impairment, with agreeableness contributing an additional $9.9 \%$ of the variance, $R^{2}$ change $=.099$, Fchange $[1,50]=17.88, p$ $<.001$. In Model 3 higher levels of interpersonal problems predicted greater social role impairment, with interpersonal problems predicting an additional $7.2 \%$ of the variance, $R^{2}$ change $=.072$, Fchange $[1,50]=11.78, p=.001$. 


\section{Additive Models of Personality Traits and Processes in Predicting Social Role Impairment}

To evaluate the impact of combining personality traits and processes in a predictive model of social role impairment, we conducted two hierarchical multiple regressions (Table 4). Given prior empirical findings substantiating the relationship between personality traits and functional impairment, we entered personality traits (neuroticism or agreeableness) into the model first, followed by personality processes (interpersonal problems) in the next step. Consistent with our hypothesis, Model 4 indicated that a combined model of neuroticism and IIP-PD-15 was significant $\left(F(6,49)=19.51, p<.001 ; \mathrm{R}^{2}=.71\right)$ and that IIP-PD-15 predicted an additional $3.3 \%$ of the variance in social role impairment above and beyond the influence of neuroticism alone, $R^{2}$ change $=.033$, Fchange [1,49] $=5.49, p=.023$. While Model 5 was significant overall, $F(6,49)=22.24, p<.001 ; \mathrm{R}^{2}=.73$, contrary to our hypothesis, a combined model of agreeableness and IIP-PD-15 scores did not significantly predict additional variance in social role impairment $\left(R^{2}\right.$ change $=.008$, Fchange $[1,49]=$ $1.41, p=.240)$ above and beyond the influence of agreeableness.

\section{Discussion}

While previous research has established the connection between impaired social adjustment for individuals with personality pathology in mixed-aged samples, limited research is available regarding the impact of personality traits and processes on functional impairment in depressed older adults (Oltmanns \& Balsis, 2011) who are often treated in primary care settings (Sirey et al., 2010). To address this gap in the literature, we aimed to examine the unique relationship between candidate indicators of personality pathology and social role impairment in a depressed sample of older adults in primary care. Building upon previous research establishing a connection between personality pathology (oftentimes within the context of depression) and impairment in social functioning in older adults (e.g. Abrams et al., 1998; Gleason et al., 2014; Weinstein et al., 2012), we aimed to elucidate how this relationship is formed and maintained by examining several predictive models.

We began our analyses examining for relationships between both maladaptive personality traits and processes and social role impairment. First we assessed for potential confounding variables, and found that depression severity, occupational status, education and race were significantly associated with social role impairment. The association between depression and social impairment is consistent with evidence both in mixed-aged (Luty, Joyce, Mulder, \& McKenzie, 2002; Newton-Howes, 2014; Serretti et al., 2013) and older adult samples (Sinclair, Lyness, King, Cox, \& Caine, 2001; Zweig \& Turkel, 2007). Findings related to the other demographic confounds and social role impairment are less consistent with available evidence from mixed-aged and older adults samples (for race see: Hernandez, Plant, SachsEricsson, \& Joiner, 2005; Plant \& Sachs-Ericsson, 2004; for education see: Chapman, Duberstein, \& Lyness, 2007; Jaconelli, Stephan, \& Chapman, 2012; Serretti et al., 2013; for occupational status see: McKee-Ryan, Song, Wanberg, \& Kinicki, 2005; Serretti et al., 2013). It is important to note that race consistently emerged as a significant predictor in our sample. It is possible that race was a proxy for an unaccounted variable (e.g. income security) that impacts perceived social role functioning. Due to the relatively limited 
evidence in this area, further research is needed to understand the relationship between these demographic and clinical variables and social role impairment, particularly in older adults.

Regarding traits and social role impairment, we found that above and beyond the influence of depression, high levels of neuroticism and low levels of agreeableness were significant contributors to social role impairment. These findings are consistent with previous research that associates low agreeableness and high neuroticism with social dysfunction in mixedaged samples (Hopwood et al., 2009; Mullins-Sweatt \& Widiger, 2010; Ozer \& BenetMartinez, 2006) and suggests that these factors function largely as expected in an older adult sample relative to previous research with younger adults. In addition, our findings lend support for a potential general personality pathology "signature" within the FFM framework (high neuroticism, low agreeableness; Saulsman \& Page, 2004) and highlight its applicability to older adults. The existence of this general "signature" does not suggest that the other FFM traits are irrelevant to personality pathology or functional impairment (Mullins-Sweatt \& Widiger, 2010; Ozer \& Benet-Martinez, 2006). Other FFM domains may be particularly useful to describe specific manifestations of personality pathology or problems in living (e.g. conscientiousness may be linked with job performance; Ozer \& Benet-Martinez, 2006) while the "signature" may signal an overall presence of PD.

Drawing upon McAdams \& Pals' model of personality (2006), we also examined the relationship between personality processes, as evidenced by chronic interpersonal difficulties (IIP-PD-15), and social role impairment (SAS-SR). We found that chronic interpersonal problems contributed to social role impairment above and beyond the influence of depression and other relevant confounds. Our findings are consistent with Hopwood and colleagues (2011) who found an association between personality pathology (i.e. PD severity and style) and social dysfunction in a mixed age sample. It is likely that some of the shared variance between the IIP-PD-15 and SAS-SR is evidence of overlap between the two measures, as they both assess for problems in the interpersonal domain. However, the IIPPD-15 and SAS-SR are only moderately correlated in our study $(r=.50)$, supporting the notion that they measure distinct constructs. Further, the SAS-SR is sensitive to state changes in interpersonal functioning while the IIP captures both trait and state aspects of interpersonal dysfunction (Vittengl, Clark, \& Jarrett, 2003). Since social role impairment is one of the most enduring effects of personality pathology (Oltmanns \& Balsis, 2011) then, following Cronbach \& Meehl's (1955) recommendation for establishing construct validity, we would argue that select personality traits and processes which correlate with social role impairment may be determined to be indicators of personality pathology in older adults.

Next, we examined whether accounting for different levels of personality functioning (e.g. maladaptive traits and processes; McAdams \& Pals, 2006) in a single model enhanced our prediction of social role impairment. We found that a combined additive model of neuroticism and IIP-PD-15 scores predicted unique variance in social role functioning above and beyond the influence of neuroticism alone. However, when examining the beta values for each variable, only IIP-PD-15 (not neuroticism) emerged as a significant predictor in the model. A combined additive model of agreeableness and IIP-PD-15 scores did not predict additional variance, although this may have been impacted by our small sample size. Additionally, while agreeableness and IIP-PD-15 scores capture different aspects of 
personality functioning, their constructs tap into similar difficulties and were strongly correlated in our study, which may make it difficult to find unique variance accounted for in an additive model. These models highlight the potential importance of accounting for not only dispositional traits when considering social role impairment, but also personality processes, particularly in the interpersonal domain.

\section{Limitations}

Our sample was comprised of generally young-old, relatively healthy, well-educated and mildly depressed participants and was relatively small, which limits out ability to generalize our findings to the population of depressed older adults. Future work should examine these relationships in a larger sample. Further, although personality pathology may be more common in depressed samples of older adults (Devenand et al., 2000), our sample was not recruited to represent a personality disordered population, which may restrict the range of personality pathology represented in our sample. Additionally, due to the cross-sectional design of our study, no assumptions of causality can be made regarding the relationship between traits, processes and social role impairment.

Although our study did not include DSM-based standardized measures of personality pathology, one item response theory study suggested that DSM criteria sets may exhibit age bias (Balsis et al., 2007). Therefore, future research may consider using DSM-related measures, which preliminary validation studies suggest may effectively screen for personality disorder in older adults (e.g. GPS: Penders, Rossi, Metsemakers, Duimel-Peeters \& van Alphen, 2016; Van Alphen, Engelen, Kuin, Hoijtink \& Derksen, 2006; HAP: Barendse, Thissen, Rossi, Oei \& Van Alphen, 2013; SIPP-SF: Rossi, Debast \& Van Alphen, 2017). While there is evidence that the FFM framework captures maladaptive poles of personality functioning (Lynam \& Widiger, 2001), the NEO-FFI assesses personality traits only at the broad domain-level rather than the facet-level, which limits our ability to examine nuanced relationships between personality traits and pathology (Bagby, Costa, Widiger, Ryder \& Marshall, 2005; Reynolds \& Clark, 2001; Samuel \& Widiger, 2008). Research establishing the relationship between the NEO-FFI and personality pathology in older adults is particularly needed. Future research may consider using trait measures specifically developed to evaluate normative and maladaptive personality (e.g. SNAP, Reynolds \& Clark, 2001; Gleason et al., 2014) when studying personality pathology. In addition, our study relied upon self-report measures, which can be influenced by participant bias, response style and memory effects.

\section{Conclusions}

This is among the first studies to link trait and process-level markers of personality pathology (traits: high $\mathrm{N}$ and low A; processes: IIP-PD-15) to social role impairment in older adults, and to promote an additive model of personality functioning in order to best capture the impact of personality pathology on important outcomes in older adults. Demographic factors such as education, race and employment status are associated with social role impairment, but merit further study. Future research should clarify the nature of a potential FFM "signature" (high N and low A) and directly assess its clinical utility in 
identifying older patients with personality pathology. Further exploration of the relationships between the different manifestations of personality qualities is important in order to both develop and test new theories of personality while also improving our understanding of when and how personality becomes maladaptive. While our findings point toward the utility of additive models of personality traits and processes, additional research with larger samples is required to be more certain of these relationships.

\section{Acknowledgments}

Disclosure Statement

The authors report no conflicts of interest.

This work was supported by the National Institute of Mental Health under Grant MH 087562

Funding

This work was supported by the National Institute of Mental Health under Grant MH 087562.

\section{References}

Abrams RC, Alexopoulos GS, Spielman LA, Klausner E, \& Kakuma T (2001). Personality disorder symptoms predict declines in global functioning and quality of life in elderly depressed patients. The American Journal of Geriatric Psychiatry, 9(1), 67-71. [PubMed: 11156754]

Abrams RC, Spielman LA, Alexopoulos GS, \& Klausner E (1998). Personality disorder symptoms and functioning in elderly depressed patients. The American Journal of Geriatric Psychiatry, 6(1), 2430. [PubMed: 9469211]

Agronin ME, \& Maletta G (2000). Personality disorders in late life: understanding and overcoming the gap in research. The American Journal of Geriatric Psychiatry, 8(1), 4-18. [PubMed: 10648290]

American Psychiatric Association. (2013). Diagnostic and statistical manual of mental disorders, (DSM-5®). Arlington, VA: American Psychiatric Publishing.

Bagby RM, Costa PT Jr, Widiger TA, Ryder AG, \& Marshall M (2005). DSM-IV personality disorders and the Five-Factor Model of personality: a multi-method examination of domain-and facet-level predictions. European Journal of Personality: Published for the European Association of Personality Psychology, 19(4), 307-324.

Bagby RM, Quilty LC, \& Ryder AC (2008). Personality and depression. The Canadian Journal of Psychiatry, 53(1), 14-25. [PubMed: 18286868]

Balsis S, Gleason ME, Woods CM, \& Oltmanns TF (2007). An item response theory analysis of DSMIV personality disorder criteria across younger and older age groups. Psychology and aging, 22(1), 171. [PubMed: 17385993]

Balsis S, Zweig R, \& Molinari V (2015). Personality disorders in later life In Lichtenberg P \& Mast B, (Eds.) Handbook of Professional Gero-Psychology: Vol. 2. Assessment, treatment, and issues of later life (pp.79-94). Washington, D.C.: American Psychological Association.

Barendse HPJ, Thissen AJC, Rossi G, Oei TI, \& Van Alphen SPJ (2013). Psychometric properties of an informant personality questionnaire (the HAP) in a sample of older adults in the Netherlands and Belgium. Aging \& mental health, 17(5), 623-629. [PubMed: 23323723]

Bender DS, Dolan RT, Skodol AE, Sanislow CA, Dyck IR, McGlashan TH, .. \& \& Gunderson JG (2001). Treatment utilization by patients with personality disorders. American Journal of psychiatry, 158(2), 295-302.

Black DW, Baumgard CH, \& Bell SE (1995). A 16-to 45-year follow-up of 71 men with antisocial personality disorder. Comprehensive Psychiatry, 36(2), 130-140. [PubMed: 7758299]

Boyle LL, Lyness JM, Duberstein PR, Karuza J, King DA, Messing S, \& Tu X (2010). Trait neuroticism, depression, and cognitive function in older primary care patients. The American Journal of Geriatric Psychiatry, 18(4), 305-312. [PubMed: 20220585] 
Carpenter D, Clarkin JF, Glick ID, \& Wilner PJ (1995). Personality pathology among married adults with bipolar disorder. Journal of affective disorders, 34(4), 269-274. [PubMed: 8550952]

Chapman B, Duberstein P, \& Lyness JM (2007). Personality traits, education, and health-related quality of life among older adult primary care patients. The Journals of Gerontology Series B: Psychological Sciences and Social Sciences, 62(6), 343-352.

Chapman BP, Lyness JM, \& Duberstein P (2007). Personality and medical illness burden among older adults in primary care. Psychosomatic Medicine, 69(3), 277-282. [PubMed: 17401059]

Chapman BP, Roberts B, Lyness J, \& Duberstein P (2013). Personality and physician-assessed illness burden in older primary care patients over 4 years. The American Journal of Geriatric Psychiatry, 21(8), 737-746. [PubMed: 23567416]

Clark DO, Von Korff M, Saunders K, Baluch WM, \& Simon GE (1995). A chronic disease score with empirically derived weights. Medical care, 33(8), 783-795. [PubMed: 7637401]

Costa PT, \& McCrae RR (1992). The five-factor model of personality and its relevance to personality disorders. Journal of Personality Disorders, 6(4), 343-359.

Cronbach LJ, \& Meehl PE (1955). Construct validity in psychological tests. Psychological bulletin, 52(4), 281-302. [PubMed: 13245896]

Devenand DP, Turret N, Moody BJ, Fitzsimons L, Peyser S, Mickle K, Nobler M, \& Roose SP (2000). Personality disorders in elderly patients with dysthymic disorder. American Journal of Geriatric Psychiatry, 8, 188-195.

Duberstein PR, Pálsson SP, Waern M, \& Skoog I (2008). Personality and risk for depression in a birth cohort of 70-year-olds followed for 15 years. Psychological medicine, 38(05), 663-671. [PubMed: 18237453]

Fiske A, Wetherell JL, \& Gatz M (2009). Depression in older adults. Annual review of clinical psychology, 5, 363-389.

Gallo JJ, Bogner HR, Morales KH, Post EP, Lin JY, \& Bruce ML (2007). The effect of a primary care practice-based depression intervention on mortality in older adults: a randomized trial. Annals of internal medicine, 146(10), 689-698. [PubMed: 17502629]

Gleason ME, Weinstein Y, Balsis S, \& Oltmanns TF (2014). The enduring impact of maladaptive personality traits on relationship quality and health in later life. Journal of personality, 82(6), 493501. [PubMed: 23998798]

Gradman T, Thompson L, \& Gallagher-Thompson D (1999). Personality Disorders and Treatment Outcome In Rosowsky E, Abrams R, Zweig R (Eds.) Personality Disorders in Older Adults: Emerging Issues in Diagnosis \& Treatment (pp. 69-94). Mahwah, NJ: Erlbaum.

Grilo CM, Stout RL, Markowitz JC, Sanislow CA, Ansell EB, Skodol AE, ... \& McGlashan TH (2010). Personality disorders predict relapse after remission from an episode of major depressive disorder: a 6-year prospective study. Journal of Clinical Psychiatry, 71(12), 1629-1635.

Hamilton M (1960). A rating scale for depression. Journal of neurology, neurosurgery, and psychiatry, 23(1), 56.

Harrison KE, Dombrovski AY, Morse JQ, Houck P, Schlernitzauer M, Reynolds CF, \& Szanto K (2010). Alone? Percieved social support and chronic interpersonal difficulties in suicidal elders. International Psychogeriatrics, 22(03), 445-454. [PubMed: 20003633]

Hengartner MP, Müller M, Rodgers S, Rössler W, \& Ajdacic-Gross V (2014). Occupational functioning and work impairment in association with personality disorder trait-scores. Social psychiatry and psychiatric epidemiology, 49(2), 327-335. [PubMed: 23835577]

Hernandez A, Plant EA, Sachs-Ericsson N, \& Joiner TE (2005). Mental health among Hispanics and Caucasians: risk and protective factors contributing to prevalence rates of psychiatric disorders. Journal of anxiety disorders, 19(8), 844-860. [PubMed: 16243634]

Hooker K, \& McAdams DP (2003). Personality reconsidered: A new agenda for aging research. The Journals of Gerontology Series B: Psychological Sciences and Social Sciences, 58(6), P296-P304.

Hopwood CJ, Malone JC, Ansell EB, Sanislow CA, Grilo CM, McGlashan TH, ... \& Gunderson JG (2011). Personality assessment in DSM-5: empirical support for rating severity, style, and traits. Journal of Personality Disorders, 25(3), 305-320. [PubMed: 21699393]

Hopwood CJ, Morey LC, Ansell EB, Grilo CM, Sanislow CA, McGlashan TH, ... \& Skodol AE (2009). The convergent and discriminant validity of five-factor traits: Current and prospective 
social, work, and recreational dysfunction. Journal of personality disorders, 23(5), 466-476. [PubMed: 19817628]

Horowitz LM, Rosenberg SE, Baer BA, Ureño G, \& Villaseñor VS (1988). Inventory of interpersonal problems: psychometric properties and clinical applications. Journal of consulting and clinical psychology, 56(6), 885-892. [PubMed: 3204198]

Hunt M (2007). Borderline personality disorder across the life span. Journal of women \& aging, 19(12), 173-191. [PubMed: 17588886]

Jaconelli A, Stephan Y, \& Chapman BP (2012). Personality and physical functioning among older adults: The moderating role of education. The Journals of Gerontology Series B: Psychological Sciences and Social Sciences, 68(4) 553-557.

Kessler RC, Birnbaum H, Bromet E, Hwang I, Sampson N, \& Shahly V (2010). Age differences in major depression: results from the National Comorbidity Survey Replication (NCS-R). Psychological medicine, 40(02), 225-237. [PubMed: 19531277]

Kim Y, \& Pilkonis PA (1999). Selecting the most informative items in the IIP scales for personality disorders: An application of item response theory. Journal of personality disorders, 13(2), 157174. [PubMed: 10372349]

Koorevaar AML, Comijs HC, Dhondt ADF, van Marwijk HWJ, Van Der Mast RC, Naarding P, .. \& Stek ML (2013). Big Five personality and depression diagnosis, severity and age of onset in older adults. Journal of affective disorders, 151(1), 178-185. [PubMed: 23820093]

Kotov R, Gamez W, Schmidt F, \& Watson D (2010). Linking "big” personality traits to anxiety, depressive, and substance use disorders: a meta-analysis. Psychological bulletin, 136(5), 768-821. [PubMed: 20804236]

Krueger RF, \& Eaton NR (2010). Personality traits and the classification of mental disorders: Toward a more complete integration in DSM-5 and an empirical model of psychopathology. Personality Disorders: Theory, Research, and Treatment, 1(2), 97-118.

Leibson CL, Garrard J, Nitz N, Waller L, Indritz M, Jackson J, .. \& Luepke L (1999). The role of depression in the association between self-rated physical health and clinically defined illness. The Gerontologist, 39(3), 291-298. [PubMed: 10396887]

Leising D, Rehbein D, \& Eckardt J (2009). The Inventory of Interpersonal Problems (IIP-64) as a screening measure for avoidant personality disorder. European Journal of Psychological Assessment, 25(1), 16-22.

Luty SE, Joyce PR, Mulder RT, \& McKenzie JM (2002). Social adjustment in depression: the impact of depression severity, personality, and clinic versus community sampling. Journal of affective disorders, 70(2), 143-154. [PubMed: 12117626]

Lynam DR, \& Widiger TA (2001). Using the five-factor model to represent the DSM-IV personality disorders: an expert consensus approach. Journal of abnormal psychology, 110(3), 401-412. [PubMed: 11502083]

Markowitz JC, Skodol AE, Petkova E, Cheng J, Sanislow CA, Grilo CM, .. \& McGlashan TH (2007). Longitudinal effects of personality disorders on psychosocial functioning of patients with major depressive disorder. Journal of Clinical Psychiatry, 68(2), 186-193.

McAdams DP, \& Pals JL (2006). A new Big Five: fundamental principles for an integrative science of personality. American Psychologist, 61(3), 204-217.

McCrae RR, \& John OP (1992). An introduction to the five-factor model and its applications. Journal of personality, 60(2), 175-215.

McKee-Ryan F, Song Z, Wanberg CR, \& Kinicki AJ (2005). Psychological and physical well-being during unemployment: a meta-analytic study. Journal of applied psychology, 90(1), 53-76.

Meyers BS, Sirey JA, Bruce M, Hamilton M, Raue P, Friedman SJ, ... \& Alexopoulos G (2002). Predictors of early recovery from major depression among persons admitted to community-based clinics: an observational study. Archives of General Psychiatry, 59(8), 729-735. [PubMed: 12150649]

Morey LC, Gunderson JG, Quigley BD, Shea MT, Skodol AE, McGlashan TH, ... \& Zanarini MC (2002). The representation of borderline, avoidant, obsessive-compulsive, and schizotypal personality disorders by the five-factor model. Journal of personality disorders, 16(3), 215-234. [PubMed: 12136679] 
Morse JQ, \& Pilkonis PA (2007). Screening for personality disorders. Journal of personality disorders, 21(2), 179-198. [PubMed: 17492920]

Mullins-Sweatt SN, \& Widiger TA (2010). Personality-related problems in living: an empirical approach. Personality disorders: Theory, research, and treatment, 1(4), 230-238.

Newton-Howes G (2014). The impact of mental state disorder and personality on social functioning in patients engaged in community mental health care. Australasian Psychiatry, 22(1), 19-22. [PubMed: 23996666]

Oltmanns TF, \& Balsis S (2011). Personality disorders in later life: Questions about the measurement, course, and impact of disorders. Annual Review of Clinical Psychology, 7, 321-349.

Oltmanns TF, Melley AH, \& Turkheimer E (2002). Impaired social functioning and symptoms of personality disorders assessed by peer and self-report in a nonclinical population. Journal of personality disorders, 16(5), 437-452. [PubMed: 12489310]

Ozer DJ, \& Benet-Martinez V (2006). Personality and the prediction of consequential outcomes. Annual. Review of. Psychology, 57, 401-421.

Penders KA, Rossi G, Metsemakers JF, Duimel-Peeters IG, \& van Alphen SP (2016). Diagnostic accuracy of the Gerontological Personality Disorder Scale (GPS) in Dutch general practice. Aging \& mental health, 20(3), 318-328. [PubMed: 25683874]

Piedmont RL, Sherman MF, \& Sherman NC (2012). Maladaptively high and low openness: The case for experiential permeability. Journal of personality, 80(6), 1641-1668. [PubMed: 22320184]

Pilkonis PA, Kim Y, Proietti JM, \& Barkham M (1996). Scales for personality disorders developed from the Inventory of Interpersonal Problems. Journal of Personality Disorders, 10(4), 355-369.

Plant EA, \& Sachs-Ericsson N (2004). Racial and ethnic differences in depression: the roles of social support and meeting basic needs. Journal of consulting and clinical psychology, 72(1), 41-52. [PubMed: 14756613]

Powers AD, Gleason ME, \& Oltmanns TF (2013). Symptoms of borderline personality disorder predict interpersonal (but not independent) stressful life events in a community sample of older adults. Journal of abnormal psychology, 122(2), 469-474. [PubMed: 23713502]

Powers AD, \& Oltmanns TF (2012). Personality disorders and physical health: A longitudinal examination of physical functioning, healthcare utilization, and health-related behaviors in middleaged adults. Journal of personality disorders, 26(4), 524-538. [PubMed: 22867504]

Reynolds SK, \& Clark LA (2001). Predicting dimensions of personality disorder from domains and facets of the five factor model. Journal of personality, 69(2), 199-222. [PubMed: 11339796]

Reynolds K, Pietrzak RH, El-Gabalawy R, Mackenzie CS, \& Sareen J (2015). Prevalence of psychiatric disorders in US older adults: findings from a nationally representative survey. World Psychiatry, 14(1), 74-81. [PubMed: 25655161]

Roberts BW, Kuncel NR, Shiner R, Caspi A, \& Goldberg LR (2007). The power of personality: The comparative validity of personality traits, socioeconomic status, and cognitive ability for predicting important life outcomes. Perspectives on Psychological Science, 2(4), 313-345. [PubMed: 26151971]

Rossi G, Debast I, \& Van Alphen SPJ (2017). Measuring personality functioning in older adults: Construct validity of the Severity Indices of Personality Functioning-Short Form (SIPP-SF). Aging \& mental health, 21(7), 703-711. [PubMed: 26923265]

Samuel DB, \& Gore WL (2012). Maladaptive variants of conscientiousness and agreeableness. Journal of personality, 80(6), 1669-1696. [PubMed: 22321159]

Samuel DB, \& Widiger TA (2008). A meta-analytic review of the relationships between the five-factor model and DSM-IV-TR personality disorders: A facet level analysis. Clinical psychology review, 28(8), 1326-1342. [PubMed: 18708274]

Saulsman LM, \& Page AC (2004). The five-factor model and personality disorder empirical literature: A meta-analytic review. Clinical Psychology Review, 23(8), 1055-1085. [PubMed: 14729423]

Schuster JP, Hoertel N, Le Strat Y, Manetti A, \& Limosin F (2013). Personality disorders in older adults: findings from the National Epidemiologic Survey on Alcohol and Related Conditions. The American Journal of Geriatric Psychiatry, 21(8), 757-768. [PubMed: 23567365] 
Segal DL, Zweig R, \& Molinari V (2012). Personality disorders in later life In Whitbourne SK \& Sliwinski MJ (Eds.), The Wiley-Blackwell Handbook of Adulthood and Aging (pp. 312-330). Oxford, UK: Wiley-Blackwell.

Seidlitz L (2001). Personality factors in mental disorders of later life. The American Journal of Geriatric Psychiatry, 9(1), 8-21. [PubMed: 11156747]

Serretti A, Chiesa A, Souery D, Calati R, Sentissi O, Kasper S, .. \& Zohar J (2013). Social adjustment among treatment responder patients with mood disorders. Journal of affective disorders, 150(3), 961-966. [PubMed: 23764379]

Sinclair PA, Lyness JM, King DA, Cox C, \& Caine ED (2001). Depression and self-reported functional status in older primary care patients. American Journal of Psychiatry, 158(3), 416-419.

Sirey JA, Banerjee S, Marino P, Bruce ML, Halkett A, Turnwald M, .. \& Kales HC (2017). Adherence to depression treatment in primary care: a randomized clinical trial. JAMA Psychiatry, 74(11), 1129-1135. [PubMed: 28973066]

Sirey JA, Bruce ML, \& Kales HC (2010). Improving antidepressant adherence and depression outcomes in primary care: the treatment initiation and participation (TIP) program. The American Journal of Geriatric Psychiatry, 18(6), 554-562. [PubMed: 20220604]

Skodol AE, Grilo CM, Pagano ME, Bender DS, Gunderson JG, Shea MT, ... \& McGlashan TH (2005a). Effects of personality disorders on functioning and well-being in major depressive disorder. Journal of psychiatric practice, 11(6), 363-368. [PubMed: 16304504]

Skodol AWE, Johnson JG, Cohen P, Sneed JR, \& Crawford TN (2007). Personality disorder and impaired functioning from adolescence to adulthood. The British Journal of Psychiatry, 190(5), 415-420. [PubMed: 17470956]

Skodol AE, Pagano ME, Bender DS, Shea MT, Gunderson JG, Yen S, .. \& McGlashan TH (2005b). Stability of functional impairment in patients with schizotypal, borderline, avoidant, or obsessivecompulsive personality disorder over two years. Psychological Medicine, 35(03), 443-451. [PubMed: 15841879]

Soeteman DI, Verheul R, \& Busschbach JJ (2008). The burden of disease in personality disorders: diagnosis-specific quality of life. Journal of Personality Disorders, 22(3), 259-268. [PubMed: 18540798]

Stern BL, Kim Y, Trull TJ, Scarpa A, \& Pilkonis P (2000). Inventory of Interpersonal Problems Personality Disorder Scales: Operating characteristics and confirmatory factor analysis in nonclinical samples. Journal of personality assessment, 74(3), 459-471. [PubMed: 10900572]

Szanto K, Dombrovski AY, Sahakian BJ, Mulsant BH, Houck PR, Reynolds CF III, \& Clark L (2012). Social emotion recognition, social functioning, and attempted suicide in late-life depression. The American Journal of Geriatric Psychiatry, 20(3), 257-265. [PubMed: 22354116]

Ustun B, \& Kennedy C (2009). What is "functional impairment"? Disentangling disability from clinical significance. World Psychiatry, 8(2), 82-85. [PubMed: 19516924]

Van Alphen SPJ, Derksen JJL, Sadavoy J, \& Rosowsky E (2012). Features and challenges of personality disorders in late life. Aging \& mental health, 16(7), 805-810. [PubMed: 22417221]

Van Alphen SPJ, Engelen GJJA, Kuin Y, Hoijtink HJA, \& Derksen JJL (2006). A preliminary study of the diagnostic accuracy of the Gerontological Personality Disorders Scale (GPS). International Journal of Geriatric Psychiatry: A journal of the psychiatry of late life and allied sciences, 21(9), 862-868.

Vine RG, \& Steingart AB (1994). Personality disorder in the elderly depressed. The Canadian Journal of Psychiatry, 39(7), 392-398. [PubMed: 7987781]

Vittengl JR, Clark LA, \& Jarrett RB (2003). Interpersonal problems, personality pathology, and social adjustment after cognitive therapy for depression. Psychological Assessment, 15(1), 29. [PubMed: 12674722]

Weinstein Y, Gleason ME, \& Oltmanns TF (2012). Borderline but not antisocial personality disorder symptoms are related to self-reported partner aggression in late middle-age. Journal of abnormal psychology, 121(3), 692. [PubMed: 22732005]

Weinstock LM, \& Whisman MA (2006). Neuroticism as a common feature of the depressive and anxiety disorders: a test of the revised integrative hierarchical model in a national sample. Journal of abnormal psychology, 115(1), 68-74. [PubMed: 16492097] 
Weiss A, Costa PT Jr, Karuza J, Duberstein PR, Friedman B, \& McCrae RR (2005). Cross-sectional age differences in personality among medicare patients aged 65 to 100 . Psychology and aging, 20(1), 182-185. [PubMed: 15769223]

Weissman M (1999). MHS Staff Social Adjustment Scale-Self-report (SAS-SR) User's Manual. North Tonawanda, NY: Multi-Health Systems.

Weissman MM, \& Bothwell S (1976). The assessment of social adjustment by self-report. Archives of General Psychiatry, 33, 1111-1115. [PubMed: 962494]

Wilson, Stroud, Durbin (2017). Interpersonal dysfunction in personality disorders: A meta-analytic review. Psychological Bulletin, 143(7), 677-734. [PubMed: 28447827]

Zweig RA, Agronin M (2011). Personality Disorders in Late Life In Agronin M, Maletta G (Eds.) Principles \& Practice of Geriatric Psychiatry, (pp. 449-469). Philadelphia: Lippincott, Williams \& Wilkins.

Zweig RA, \& Turkel E (2007). The social adjustment scale-self report: psychometric properties for older adults. Psychological reports, 101(3), 920-926. [PubMed: 18232450] 


\section{Clinical Implications}

1. In depressed older adults, maladaptive personality traits (high neuroticism and low agreeableness) and processes (high IIP-PD-15) are associated with an important outcome in clinical work, social functioning.

2. If these findings are replicated in future research with other clinical samples, they argue for clinical screening of personality pathology in depressed older adults utilizing both personality trait and process measures.

3. Successful screening of personality pathology in older, depressed primary care patients could assist clinicians to augment standard approaches with targeted psychotherapeutic treatment strategies and techniques for individuals with personality pathology (e.g. a cohesive team approach with interdisciplinary staff). In addition, positive screens for personality pathology may prompt clinicians to evaluate the need for patient referrals to relevant resources (e.g. psychotherapy, case management). 


\section{Table 1}

Demographic Characteristics, descriptive findings and internal reliability for primary variables

\begin{tabular}{|c|c|c|c|}
\hline Variable & $N$ & Mean (SD) or Percentage (\%) & Alpha \\
\hline Age & 56 & $66.8(8.75)$ & - \\
\hline \multicolumn{4}{|l|}{ Gender } \\
\hline Female & 43 & 76.8 & - \\
\hline \multicolumn{4}{|l|}{ Race/Ethnicity } \\
\hline White & 34 & 60.7 & - \\
\hline \multicolumn{4}{|l|}{ Marital Status } \\
\hline Married & 13 & 23.2 & - \\
\hline Never Married & 17 & 30.4 & - \\
\hline Once Married & 26 & 46.4 & - \\
\hline Education & 56 & $14.4(2.88)$ & - \\
\hline \multicolumn{4}{|l|}{ Occupational Status } \\
\hline Employed/Retired & 40 & 71.4 & - \\
\hline Unemployed/On Disability & 16 & 28.6 & - \\
\hline \multicolumn{4}{|l|}{ Living Situation } \\
\hline With Others & 30 & 53.6 & - \\
\hline Alone & 26 & 46.4 & - \\
\hline Chronic Disease Score & 56 & $3.9(2.66)$ & \\
\hline Depression Severity (HAM-D) & 56 & $16.5(9.32)$ & \\
\hline \multicolumn{4}{|l|}{ Personality Variables } \\
\hline NEO neuroticism & 56 & $22.5(7.35)$ & .78 \\
\hline NEO extroversion & 56 & $24.6(6.20)$ & .70 \\
\hline NEO openness & 56 & $28.3(5.03)$ & .50 \\
\hline NEO agreeableness & 56 & $32.6(5.07)$ & .59 \\
\hline NEO conscientiousness & 56 & $31.7(6.72)$ & .79 \\
\hline IIP-PD-15 & 56 & $15.6(10.09)$ & .85 \\
\hline \multicolumn{4}{|l|}{ Social Functioning (SAS-SR) } \\
\hline Overall Score & 56 & $2.24(.54)$ & $.59^{a}$ \\
\hline
\end{tabular}

Note.

${ }^{a}$ Consistent with standardized administration, all participants did not answer all items on the SAS-SR, as they were asked to only respond to relevant domains. Cronbach's alpha was calculated for each SAS-SR subscale, based on participants who answered all items for that sub-scale, and the above value is the mean internal consistency of the sub-scales. 
Table 2

Pearson correlation between personality (NEO-FFI and IIP-PD-15), demographic variables and social role impairment (SAS-SR)

\begin{tabular}{|c|c|c|c|c|c|c|c|}
\hline & 1 & 2 & 3 & 4 & 5 & 6 & 7 \\
\hline 1. NEO_N & & $-.52^{* * *}$ & $.56^{* * * *}$ & $.64^{* * * *}$ & -.22 & $.68^{* * * *}$ & .01 \\
\hline 2. NEO_A & & & $-.67^{* * *}$ & $-.58^{* * *}$ & .02 & $-.35^{* *}$ & -.04 \\
\hline 3. IIP-PD-15 & & & & $.50^{* * * *}$ & -.12 & $.28^{*}$ & .12 \\
\hline 4. SAS-SR (overall) & & & & & $-.27^{*}$ & $.68^{* * *}$ & .05 \\
\hline 5. Education & & & & & & -.07 & -.03 \\
\hline 6. Depression Severity (HAM-D) & & & & & & & -.05 \\
\hline 7. Chronic Disease Score & & & & & & & \\
\hline
\end{tabular}

Note. N=56.

$p<.05$

*** $p<.01$

**** $p<.001$ 
Table 3

Models of personality traits and processes predicting social role impairment (Overall SAS-SR)

\begin{tabular}{lcccccc}
\hline & \multicolumn{2}{c}{ Model 1 } & \multicolumn{2}{c}{ Model 2 } & \multicolumn{2}{c}{ Model 3 } \\
\hline Variables & $\boldsymbol{\beta}$ & SE & $\boldsymbol{\beta}$ & SE & $\boldsymbol{\beta}$ & SE \\
\hline Depression Severity (HAM-D) & $0.45^{* * *}$ & 0.01 & $0.56^{* * * *}$ & 0.01 & $0.58^{* * * *}$ & 0.01 \\
Occupational Status & -0.05 & 0.11 & 0.03 & 0.10 & -0.03 & 0.10 \\
Education & -0.05 & 0.02 & -0.13 & 0.02 & -0.09 & 0.02 \\
Race & $-0.35^{* * * *}$ & 0.10 & $-0.31^{* * *}$ & 0.09 & $-0.32^{* * * *}$ & 0.09 \\
NEO_N & $0.30^{*}$ & 0.01 & -- & -- & -- & -- \\
NEO_A & -- & -- & $-0.35^{* * *}$ & 0.01 & -- & -- \\
IIP-PD-15 & -- & -- & -- & -- & $0.28^{* *}$ & 0.00 \\
\hline
\end{tabular}

Note.

* $p<.05$

*** $p<.01$

**** $p<.001$ 
Table 4

Additive models of personality traits and processes predicting social role impairment (SAS-SR)

\begin{tabular}{lcccc}
\hline & \multicolumn{2}{c}{ Model 4 } & \multicolumn{2}{c}{ Model 5 } \\
\hline Variables & $\boldsymbol{\beta}$ & SE & $\beta$ & SE \\
\hline Depression Severity (HAM-D) & $0.50^{* * *}$ & 0.01 & $0.55^{* * *}$ & 0.01 \\
Occupational Status & -0.03 & 0.10 & 0.02 & 0.10 \\
Education & -0.06 & 0.02 & -0.11 & 0.02 \\
Race & $-0.33^{* * *}$ & 0.09 & $-0.31^{* * *}$ & 0.09 \\
NEO_N & 0.15 & 0.01 & -- & -- \\
NEO_A & -- & -- & $-0.27^{*}$ & 0.01 \\
IIP-PD-15 & $0.22^{*}$ & 0.01 & 0.12 & 0.01 \\
\hline
\end{tabular}

Note.

${ }^{*}<.05$

*** $p<.01$

**** $p<.001$ 